The Harvard College Observatory Report.-The annual report of the director of the Astronomical Observatory of Harvard College for the year ending September 30, I9I4, indicates the completion of a large amount of work in both observation and publication. Prof. E. C. Pickering refers in the first place to the principal work of the observatory, namely, its publications and the importance of issuing these as soon as possible to prevent loss by fire. Thus observations from $1892-1912$ with the 15 -in. equatorial, from $1888-98$ with the 8 -in. transit circle, and from 1898 -19 I2 with the I2-in. meridian photometer are now printed, and the discussions are in progress. The director directs attention to the improvement in photographic processes resulting in the replacement of practically all visual work. The report then describes in more detail the work of the Henry Draper Memorial, the principal research of which is the New Draper Catalogue; last year Miss Cannon classified 60,386 spectra, making a total of $160,54 \mathrm{I}$. The activities of the Boyden department, the Bruce photographic telescope, and the Blue Hill Meteorology Observatory are briefly summarised, while among the many items mentioned under the heading "Miscellaneous" the work of Prof. W. H. Pickering at the Mandeville Station, in Jamaica, is described, much time having been devoted to the study of the planet Mars during its recent opposition.

Star Charts for Meteor Observers.-One of the contributions to the January number of the Journal of the Royal Astronomical Society of Canada (vol. ix., No. I, p. 7) is entitled "A Gnomonic Star Atlas," and contains a set of thirteen maps, prepared by Mr. Reynold $K$. Young, intended to facilitate the observation of meteors and the plotting of their paths. The method of the projection of the map is such that great circles in the sky are equivalent to straight lines on the map, thus making the plotting of the meteor trails more easy. The maps are devoid of unnecessary detail. The positions of the stars are given for the epoch 1900 correct to within one-tenth of a degree, and all stars down to $5^{\text {th }}$ magnitude and the brighter variables are included. A good margin of overlap has been allowed in each map, which should prove very useful.

\section{FLUCTUATIONS OF TEMPERATURE IN EUROPE AND AMERICA.}

$M$ R. H. ARCTOWSKI, in a paper published in $M$ vol. xxiv. of the Annals of the New York Academy of Sciences, considers the problem of variation of temperature over the whole earth. After a brief statement of the general problem and the methods by which it may be attacked, he explains that he could not deal single-handed with the arrangement and discussion of the actual values even over the whole of the northern hemisphere, and confines himself to the detailed survey of the variations over North America and Europe. He also compares the results with one. or two representative equatorial and southern hemisphere stations. From a study of the values at one of these, Arequipa, in Peru, he deduces that the temperature changes are partly of a short period of about fifty-five days, brachypleionian waves; partly of a long period of twenty years or so, macropleionian waves; and partly of an intermediate period of between one and two years, pleionian waves.

In dealing with the longer periods the normal annual variation is eliminated by taking a series of means for twelve months beginning with each consecutive month of time. For the European stations he finds that the continental ones resemble Arequipa in having marked pleionian waves, while those staNO. 2369, VOL. 95] tions near the Atlantic are characterised mainly by brachypleionian variations.

In an earlier paper Mr. Arctowski dealt with the period $1891-1900$, and he takes the mean values for this period as normals, and plots on maps the difference from normal of the values during each year of the decade 1900-09. The areas where the differences are positive he calls thermopleions, and the areas of negative differences antipleions. He finds that certain years, in particular 1900, 1908, are characterised by thermopleionian areas, while others, such as I904, I907, are years of antipleions. The most important cause of these differences is the variation of solar radiation, but there are also supplementary causes such as the presence of volcanic dust in large quantities, or exceptional ice conditions in the polar regions.

Many of the maps which illustrate the results of the investigation are on a very small scale; the course of the thermopleions and thermomeions is obscured by the attempt to show relatively microscopical geographical details.

Mr. Arctowski finds it astonishing that after all the efforts which are made to organise and maintain meteorological stations all over the world, the actual results of the work are so inaccessible. Even for the area with which he dealt he could only get much of the data by writing personally to the directors of the different meteorological institutes. This is a defect which will be remedied when meteorologists of different countries undertake to contribute to a central bureau representative regional values based on a selection of stations which can only be chosen satisfactorily by the local organisation.

There is another defect which is almost more serious, viz., the lack of continuity in the records for individual stations due to changes of situation or instruments. For example, Mr. Arctowski finds that the difference of temperature between Chicago and Milwaukee was nearly $4^{\circ} \mathrm{F}$. in the decade $1873-82$, while in the decade $1896-1909$ the difference was only $2^{\circ} \mathrm{F}$. The change is almost certainly due to change of instrument or site, and as it is of the same order of magnitude as the changes with which he deals, it indicates the need for great caution.

The difficulty of securing comparable continuous records is indeed one of the most serious problems with which organised meteorology has to deal.

E. G.

\section{REFINING GOLD BY ELECTROLYSIS.}

THE problem presented by the necessity of refining gold was one for which a solution was sought at least as early as the time, about B.c. 700, when coins were first manufactured in the Western world. Apart from toughening or the removal of base metals, which was sufficiently cared for by the ancient process of cupellation, it is clear that some measure of success attended the efforts made to part gold and silver. Thus, some of the ancient Greek coins containing 997 or 998 per 1000 of gold. The earliest parting process used was one of cementation, which was succeeded by the nitric acid process. At the present day chlorine is the predominant agent for parting gold from silver in Australia, electrolysis in America, and sulphuric acid in Europe.

The electrolytic process was brought forward by Charles Watt, at Sydney, in 1863 , and was first put into operation by Wohlwill at Hamburg in 1878 and by Tuttle at the Philadelphia Mint in I902. In the gold chloride process the solution used in the bath

1 Abstract of the presidential address delivered before the Institution of Mining and Metallurgy on March 18, by Sir T. K. Rose. 